\title{
Live single cell analysis using synchrotron FTIR microspectroscopy: Development of a simple dynamic flow system for prolonged sample viability
}

DOI:

10.1039/C8AN01566J

\section{Document Version}

Accepted author manuscript

Link to publication record in Manchester Research Explorer

Citation for published version (APA):

Doherty, J., Raoof, A., Hussain, A., Wolna, M., Cinque, G., Brown, M., Gardner, P., \& Denbigh, J. (2019). Live single cell analysis using synchrotron FTIR microspectroscopy: Development of a simple dynamic flow system for prolonged sample viability. Analyst, 144(3), 997-1007. https://doi.org/10.1039/C8AN01566J

\section{Published in:}

Analyst

\section{Citing this paper}

Please note that where the full-text provided on Manchester Research Explorer is the Author Accepted Manuscript or Proof version this may differ from the final Published version. If citing, it is advised that you check and use the publisher's definitive version.

\section{General rights}

Copyright and moral rights for the publications made accessible in the Research Explorer are retained by the authors and/or other copyright owners and it is a condition of accessing publications that users recognise and abide by the legal requirements associated with these rights.

\section{Takedown policy}

If you believe that this document breaches copyright please refer to the University of Manchester's Takedown Procedures [http://man.ac.uk/04Y6Bo] or contact uml.scholarlycommunications@manchester.ac.uk providing relevant details, so we can investigate your claim.

\section{OPEN ACCESS}




\section{Analyst}

\section{Accepted Manuscript}

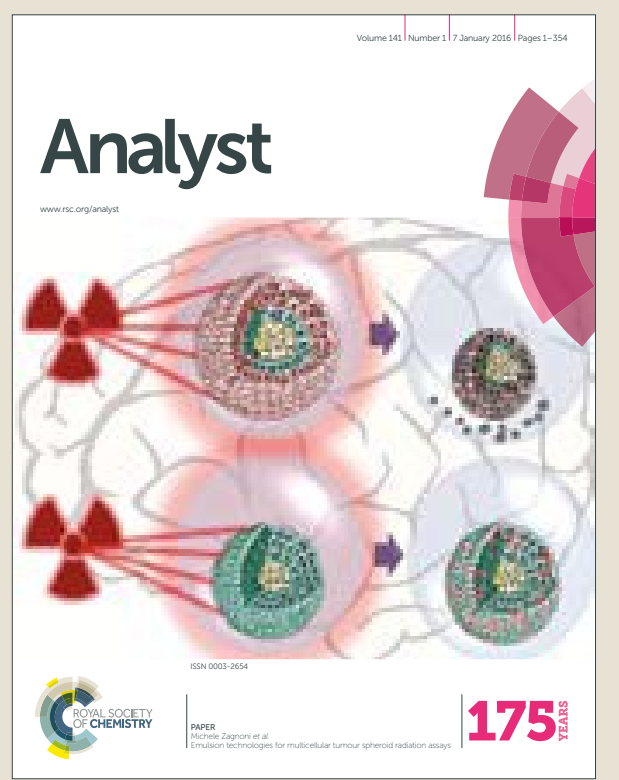

This is an Accepted Manuscript, which has been through the Royal Society of Chemistry peer review process and has been accepted for publication.

Accepted Manuscripts are published online shortly after acceptance, before technical editing, formatting and proof reading. Using this free service, authors can make their results available to the community, in citable form, before we publish the edited article. We will replace this Accepted Manuscript with the edited and formatted Advance Article as soon as it is available.

You can find more information about Accepted Manuscripts in the author guidelines

Please note that technical editing may introduce minor changes to the text and/or graphics, which may alter content. The journal's standard Terms \& Conditions and the ethical guidelines, outlined in our author and reviewer resource centre, still apply. In no event shall the Royal Society of Chemistry be held responsible for any errors or omissions in this Accepted Manuscript or any consequences arising from the use of any information it contains. 


\title{
Live single cell analysis using synchrotron FTIR microspectroscopy: development of a
} simple dynamic flow system for prolonged sample viability

\author{
James Doherty, ${ }^{\mathrm{a}, \mathrm{b}, \mathrm{c}}$ Alan Raoof, ${ }^{\mathrm{d}}$ Ansaf Hussain, ${ }^{\mathrm{d}}$ Magda Wolna, ${ }^{\mathrm{c}}$ Gianfelice Cinque,${ }^{\mathrm{c}}$ Michael \\ Brown, ${ }^{\mathrm{e}}$ Peter Gardner ${ }^{\mathrm{a}, \mathrm{b}^{*}}$ and Joanna Denbigh ${ }^{\mathrm{d}}$ \\ ${ }^{a}$ Manchester Institute of Biotechnology, University of Manchester, 131 Princess Street, \\ Manchester, M1 7DN, UK \\ ${ }^{\mathrm{b}}$ School of Chemical Engineering and Analytical Science, University of Manchester, Oxford \\ Road, M13 9PL, UK \\ ${ }^{c}$ Diamond Light Source, Diamond House, Harwell Science and Innovation Campus, Didcot, \\ Oxfordshire, OX11 0DE, UK \\ ${ }^{\mathrm{d}}$ Biomedical Research Centre, School of Environment and Life Sciences, University of Salford, \\ Salford, M5 4WT \\ e GUCR Group, Division of Cancer Science, School of Medical Sciences, Faculty of Biology, \\ Medicine and Health, University of Manchester, M20 4GJ, UK \\ * Co-corresponding authors \\ peter.gardner@manchester.ac.uk; j.1.denbigh@salford.ac.uk
}

\begin{abstract}
Synchrotron radiation Fourier transform infrared microspectroscopy (SR-microFTIR) of live biological cells has the potential to provide far greater biochemical and morphological detail than equivalent studies using dehydrated, chemically-fixed single cells. Attempts to measure live cells using microFTIR are complicated by the aqueous environment required and corresponding strong infrared absorbance by water. There is also the additional problem of the limited lifetime of the cells outside of their preferred culture environment. In this work, we outline simple, costeffective modifications to a commercially available liquid sample holder to perform single live cell analysis under an IR microscope and demonstrate cell viability up to at least 24 hours. A study using this system in which live cells have been measured at increasing temperature has shown spectral changes in protein bands attributed to $\alpha-\beta$ transition, consistent with other published work, and proves the ability to simultaneously induce and measure biochemical changes. An additional study of deuterated palmitic acid ( $\left.\mathrm{D}_{31}-\mathrm{PA}\right)$ uptake at different timepoints has made use of over 200 individual IR spectra collected over $\sim 4$ hours, taking advantage of the ability to maintain viable cell samples for longer periods of time in the measurement environment, and therefore acquire greatly increased numbers of spectra without compromising on spectral quality. Further developments of this system are planned to widen the range of possible experiments, and incorporate more complex studies, including of drug-cell interaction.
\end{abstract}




\section{Introduction}

Fourier transform infrared microspectroscopy (microFTIR) is a well-established tool for the study of biological cells. Infrared (IR) spectra of cells have been used to monitor responses to drug treatment ${ }^{1-8}$ and other external chemical and/or physical stimuli. ${ }^{9-12}$ Increasingly, there is a desire to study living cells as they respond to stimuli in real time. ${ }^{13-16}$

The study of biological cells using microFTIR has historically been limited by the use of chemically or cryogenically fixed, dried samples. While there are clear benefits to this type of sample preparation - the easy handling of samples post-fixation, and the ability to return to the same sample for repeat measurement since IR is a non-destructive measurement technique chemical fixatives are known to affect various cellular structures, ${ }^{17-19}$ limiting the interpretation of the resulting spectra.

Cell dehydration can affect the position, intensity and ratio of bands across the spectrum ${ }^{20-22}$, in particular DNA bands that become harder to distinguish from those of proteins, RNA and carbohydrates. ${ }^{23}, 24$ While fixation allows the broad biochemical structure of the cell to be maintained, subtle differences between samples as a result of external stimuli may be lost.

In contrast, studies of living cells have been proven to provide both biological and morphological detail that was previously lost when using fixed samples, especially when live cell analysis has been combined with the increased brilliance of a synchrotron radiation (SR) source. ${ }^{25-33}$

The study of living cells, however, provides a range of challenges to bioanalysts. Live cells require an aqueous environment to remain viable for any significant length of time, and water presents two significant problems for IR spectroscopists. Firstly, the strength of the water absorption of IR prevents sufficient light from reaching the sample to give a good signal and therefore high quality absorption data. Secondly, the position of the $\mathrm{O}-\mathrm{H}$ bending and stretching modes at $\sim 1650$ and $3000-3500 \mathrm{~cm}^{-1}$ respectively, and the dominance of the water bands over the remainder of the spectrum obscures key biological information relating to protein and lipid bands. ${ }^{34,35}$ This makes the extraction of biochemical information difficult. ${ }^{36}$

A range of solutions to the water problem have been proposed. These range from simply ignoring the affected spectral region ${ }^{37}$ - which is clearly limiting due to the amount of biochemical information being lost - to a range of water subtraction methods $9,19,27,38$. These corrections vary in several ways, with a lack of general consensus over the optimal method. Published methods use different wavenumber ranges as a reference to scale the water spectrum being removed - one proposed method optimises the flatness of the baseline in the 1800-2500 $\mathrm{cm}^{-1}$ region, where a water combination band is present, avoiding biochemical signals. 9,19 Another approach uses an algorithm that delivers the approximately same gradient on the baseline in two regions $\sim 1720-2800 \mathrm{~cm}^{-1}$ and $3000-3060 \mathrm{~cm}^{-1}$ on either side of the C-H stretching region $\sim 2900 \mathrm{~cm}^{-1}$. Over or under subtraction of water severely distorts this baseline in this region, particularly on the high wavenumber side, so the algorithm adds water back into 
the basic water subtracted spectrum to minimise the difference in the slope. ${ }^{38}$ A third published method takes a reference spectrum through an area of cell-free media, and removes the water contribution through a ratio to a background taken through an empty sample holder, before analysing the spectra in second derivative. ${ }^{39}$

The lack of consensus in this field highlights the fact that the removal of water from a biological IR spectrum is a non-trivial issue. The spectrum of water interacting with biological components will behave differently to that of pure water ${ }^{13}$, and therefore the subtraction of a pure water spectrum is not ideal. Likewise, removing the entire water contribution is also problematic, as structural water can account for $\sim 70 \%$ of the mass of an average cell. ${ }^{40}$

An alternative proposed solution to the water problem has been to replace the aqueous solution with deuterated water $\left(\mathrm{D}_{2} \mathrm{O}\right)$, due to its similar physical properties but significantly different IR absorption spectrum to water. This allows for both an unobstructed interpretation of the Amide I band, and thicker fluid layers of up to $20 \mu \mathrm{m} .{ }^{41}$ However, the resulting red-shift of the Amide I band ${ }^{42}$, and the toxic effect of $\mathrm{D}_{2} \mathrm{O}$ on cell viability over time ${ }^{43-46}$, render it an unsuitable bulk fluid for the majority of studies, with the exception of those focused on isotopic exchange and using $\mathrm{D}_{2} \mathrm{O}$-resilient cells.

The study of living cells in a static aqueous environment is a significant advance, enabling monitoring of cell samples without the spectral effects of chemical fixation. There remains little consensus on the ideal pathlength through aqueous solution for live cell studies, with published work featuring spectra acquired using spacers as small as $4 \mu \mathrm{m}{ }^{38}$, and as large as $20 \mu \mathrm{m} .{ }^{15}$ Compression of the cells during measurement is a significant consideration due to the physical, morphological stress exerted on the cells which can influence the resulting spectra. ${ }^{9,19,47}$ This includes, but is not limited to, variation in Amide I/II peak height ratio, and changes in protein and lipid concentrations which can be permanent under extreme deformation. The selection of a spacer size is therefore a compromise between spectral quality - reducing the water contribution as much as possible - while maintaining the cell in as healthy an environment as possible.

Previous work ${ }^{27}$ has demonstrated a water correction procedure that determines the proportion of water to be removed through a least squares fit to a Matrigel reference spectrum. This has been able to obtain good quality spectra through an aqueous pathlength of up to $12 \mu \mathrm{m}$, using the enhanced brightness of a synchrotron IR source to penetrate the water layer and provide good spatial and spectral resolution and high signal-to-noise. ${ }^{29,} 30,39,42,48,49$ This work relies on the measurement of harvested living cells suspended in phosphate buffered saline (PBS) and held in a 'sandwich' of calcium fluoride $\left(\mathrm{CaF}_{2}\right)$. The survival time of cells in this environment is limited, and therefore so is the time available for data acquisition.

The incorporation of microfluidic devices (MD) into live cell FTIR measurements can allow for the maintenance of cell viability for a number of hours, allowing for both longer term study of samples and measuring the real-time response to a chemical stimulus. 
In its simplest form, a MD exchanges spent growth medium for fresh growth medium, 50 and can be adapted from devices designed for optical microscopy by simple switching standard glass windows with an IR-transparent material. 12, 13, 51 More complex, bespoke designs incorporate temperature control and cell and/or medium-free areas for background scans, alongside medium exchange. ${ }^{19,52}$

For this study, a demountable liquid sample holder (Harrick) has been modified for use as a dynamic-mode live cell analysis system, with provision for medium exchange, a heating jacket to help regulate temperature, and a hydrophobic barrier to facilitate flow within a $10 \mu \mathrm{m}$ thick gold spacer.

Two key experiments have been carried out to demonstrate different uses of this system. In the first, the temperature of the heating jacket is increased in stages and a relatively small number of cells analysed at each temperature, to monitor infrared spectral changes brought about as a result of increasing temperature. In the second, cells are treated with $\mathrm{D}_{31}$ deuterated palmitic acid $\left(\mathrm{D}_{31^{-}}\right.$ PA) for a range of incubation times, prior to the sample being assembled in the modified liquid sample holder, and a large number of cells ( 200) measured over approximately four hours. The use of deuterated fatty acid (D-FA) allows uptake to be monitored through C-D peaks in the 2000-2300 $\mathrm{cm}^{-1}$ region which do not interfere with any other biological signal in the spectrum. ${ }^{11}$ These experiments test the ability of the design to a) induce and simultaneously monitor biochemical changes in the cells, and b) maintain a live cell sample over a significantly increased measurement time.

\section{Methodology}

\section{Cell Culture}

SKOV3 ovarian cancer cells were grown in DMEM culture media, containing 10 vol\% bovine serum, 1\% 200mM L-glutamine, 1\% penicillin-streptomycin and 1\% MEM non-essential amino acid solution, in T25 cell culture flasks at $37{ }^{\circ} \mathrm{C}$ and $5 \% \mathrm{CO}_{2}$. Approximately 36 hours before measurement, cells were harvested using trypsin and seeded onto $2 \mathrm{~mm}$ thick, $25 \mathrm{~mm}$ diameter calcium fluoride $\left(\mathrm{CaF}_{2}\right)$ windows in a 6-well plate. These windows had previously been sterilised in $70 \%$ ethanol for at least 30 minutes, and had a channel drawn on using a hydrophobic pen to confine the media flow to the sample area.

Cells were grown to $\sim 50 \%$ confluency, providing sufficient space for medium to flow and reach all cells, and allowing good separation of cells for single cell analysis. ${ }^{38}$ Higher levels of confluency could lead to significantly reduced flow rate and a highly uneven distribution of fresh media around the cells.

For the study of $\mathrm{D}_{31}$-PA uptake, SKOV3 cells were exposed to serum-free DMEM media for between 12 and 24 hours prior to $\mathrm{D}_{31}$-PA exposure, and then treated with $50 \mu \mathrm{M} \mathrm{D}_{31}$-PA (Sigma- 
Aldrich, UK) in ethanol for either $15,30,60$ or 90 minutes, or 4 or 24 hours before being removed for measurement.

\section{Development of a Simple Dynamic Flow System}

A range of tests were performed in order to optimise parameters for use of the dynamic flow system under the IR microscope (Hyperion 3000, Bruker). The sample holder for this work was initially designed for the use of $2 \mathrm{~mm}$ thick, $25 \mathrm{~mm}$ diameter windows, and has been adapted for use with an IR microscope with Cassegrain 36x optics on the MIRIAM B22 beamline at Diamond Light Source (DLS). The enhanced magnification achieved single-cell resolution and, by exploiting the SR-IR brightness, obtained good signal-to-noise through aqueous solution. A flow-rate of $1 \mu \mathrm{L} / \mathrm{min}$ was chosen in order to fully replenish media in the sample chamber in several minutes, which is broadly consistent with similar work. ${ }^{38}$ In order to ensure that the experiment began with fresh media, a higher flow-rate of $10 \mu \mathrm{L} / \mathrm{min}$ was used for approximately 3 minutes, and then reduced to $1 \mu \mathrm{L} / \mathrm{min}$ once flow had been observed.

Tests were carried out with $1 \mathrm{~mm}$ thick windows, in an attempt to improve the low wavenumber substrate cut-off, with two $1 \mathrm{~mm}$ o-rings added to the set-up, but this was susceptible to leaking and inconsistent flow. When the sample holder was assembled with two $2 \mathrm{~mm}$ thick windows, and operated at a consistent flow-rate of $1 \mu \mathrm{L} / \mathrm{min}$, the system was found to not be susceptible to leakage or window breakage over the course of $>12$ hours.

The dynamic system used in this work was assembled through simple and inexpensive modifications using commercially available materials. $10 \mu \mathrm{m}$ gold spacers were cut to allow flow into and out of the sample chamber. Teflon tubing and associated Luer fittings were purchased from Darwin Microfluidics (France), with the only bespoke component being a heating jacket for the sample holder developed by support staff at DLS. The assembly of the flow system is shown in Figure 1. 


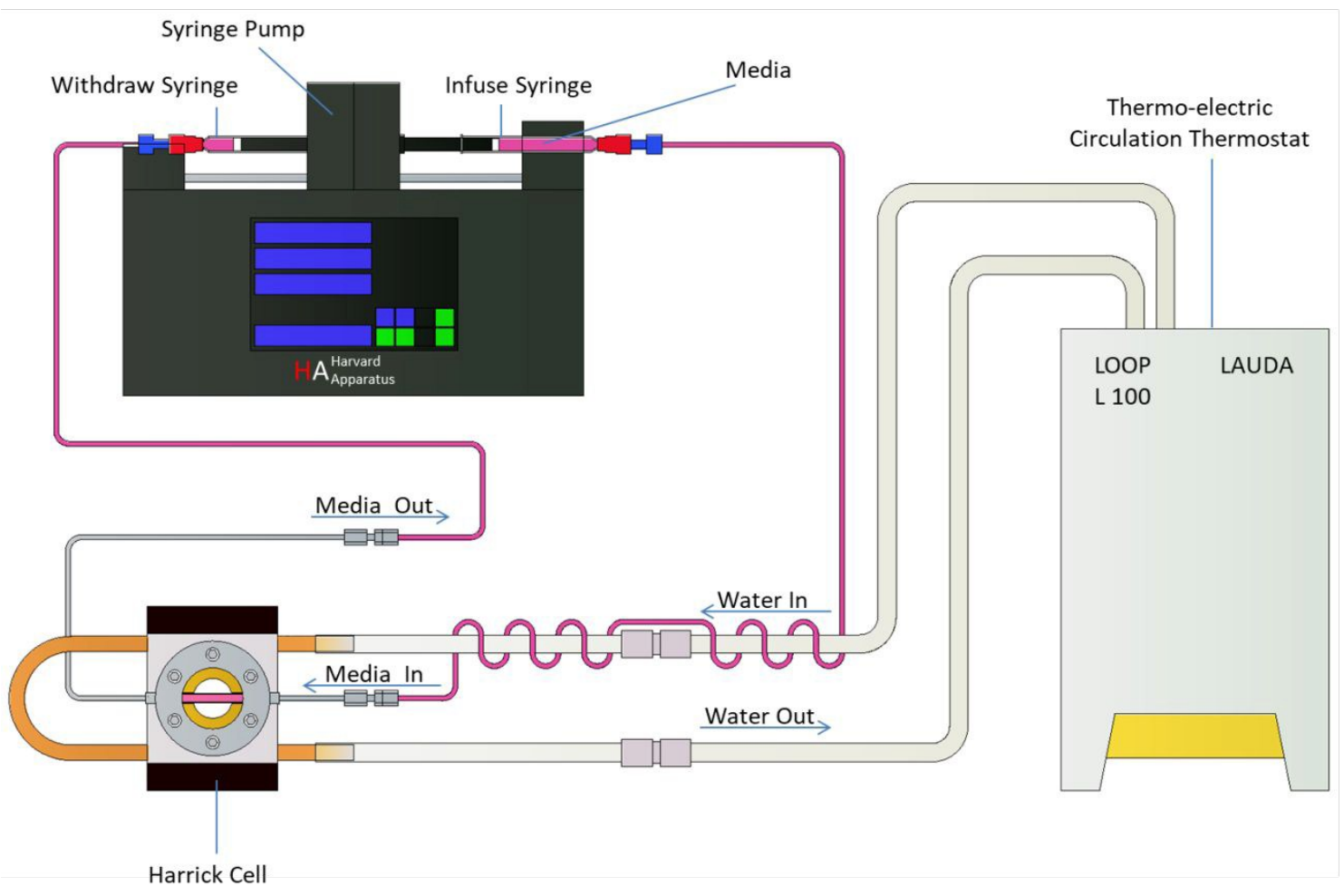

Figure 1 - Assembly of the flow system, showing the syringe pump, heating system, and modified liquid sample holder.

The consistency and reproducibility of the flow through the sample chamber was improved by depositing a hydrophobic material onto the $\mathrm{CaF}_{2}$ window, using a peroxidase-antiperoxidase (PAP) pen, to create a channel from the inlet to the outlet. A PAP pen is a commercially available tool that is used to deposit a thin, visible hydrophobic film, comprised of a formulation of Abzol, butadiene rubber and Ligroin. 53, 54 PAP pens are regularly used in immunohistochemistry experiments.

As well as improving flow through the sample holder, the use of a hydrophobic barrier ensured the presence of a dry, sample-free area for the collection of background measurements. The final assembly of the sample holder uses a cut $10 \mu \mathrm{m}$ gold spacer, and a channel comprised to two parallel hydrophobic barriers, with a heating jacket mounted around the outside of the sample chamber. The final assembly of the modified liquid sample holder is shown in Figure 2.

Tests using trypan blue staining and an automated cell counter confirmed that growing SKOV3 cells on $\mathrm{CaF}_{2}$ windows marked with the hydrophobic material had no identifiable difference on sample viability. Furthermore, tests of the sample holder assembled in this way indicated no impact from the hydrophobic channel on the pathlength through the sample area, or on the resulting spectra. 


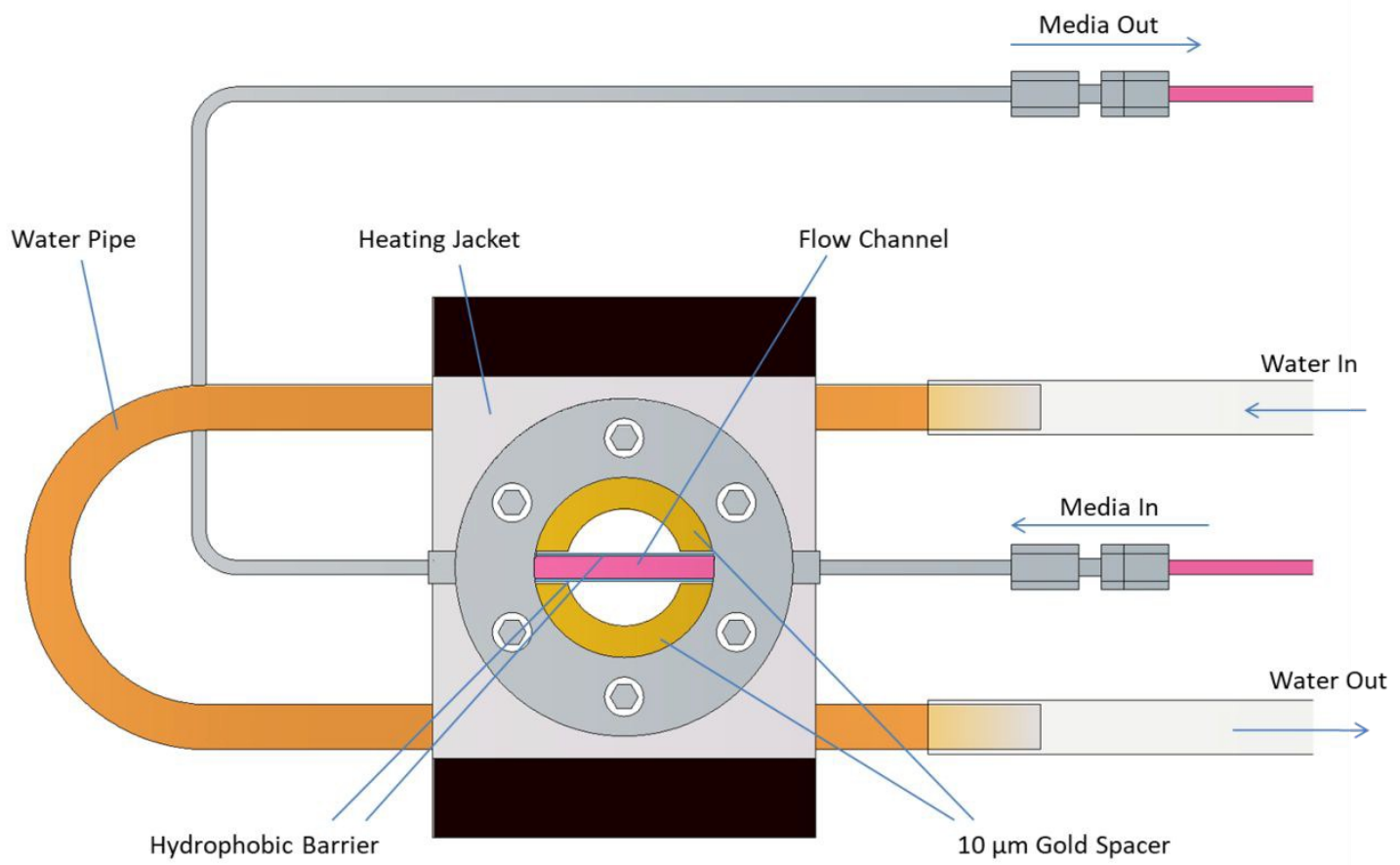

Figure 2 - Diagram of the assembly of the modified Harrick liquid sample holder. The heating jacket is shown around the sample chamber, and the inlet and outlet flow from the sample holder is indicated. Inside the sample chamber, the $10 \mu \mathrm{m}$ gold spacer, hydrophobic barriers and the flow channel are all highlighted.

\section{Sample Holder Assembly}

Viability Study: A $10 \mathrm{~mL}$ syringe (Hamilton 1000 series) was filled with complete DMEM media that had been stored in the incubator at $37{ }^{\circ} \mathrm{C}$ and $5 \% \mathrm{CO}_{2}$ for a minimum of 1 hour prior to assembly. The plunger was depressed until the entire inlet line, up to the entry point to the sample holder, was filled with media. The syringe was then loaded into the push/infusion side of a PHD Ultra Push/Pull Infusion/Withdrawal PC4 70-3009 syringe pump, with a second, empty syringe connected to the outlet line and loaded into the pull/withdrawal side.

The sample window was cleaned and dried outside of the hydrophobic channel using a cotton bud, and then loaded into the modified liquid sample holder, on top of a $1 \mathrm{~mm}$ thick o-ring, such that the hydrophobic channel was aligned with the inlet and outlet channels of the holder. A 10 $\mu \mathrm{m}$ gold-coated spacer, cut to allow flow through the channel, was then placed on top, followed by a second $2 \mathrm{~mm}$ thick, $25 \mathrm{~mm}$ diameter window. The sample holder was screwed together, with a heating jacket secured around the sample chamber and connected to a heater (Lauda L100).

Thermal Stress Study: Sample holder assembly for the thermal stress study was as described above, with several exceptions. A $1 \mathrm{~mL}$ Hamilton syringe was used, as a reduced total volume of fresh media was required over the duration of the thermal stress study. In the assembly of the 
sample holder, the second $\mathrm{CaF}_{2}$ window was replaced by a $1 \mathrm{~mm}$ thick, $\mathrm{CaF}_{2}$ slide, with a custom-designed $1 \mathrm{~mm}$ thick steel washer placed above this, the bottom of which was coated in a layer of hydrophobic material from the PAP pen. The reduced $\mathrm{CaF}_{2}$ path and therefore moved the lower wavenumber substrate cut-off from $\sim 1200 \mathrm{~cm}^{-1}$ to $\sim 1150 \mathrm{~cm}^{-1}$, allowing access to more of the spectral range.

Palmitic Acid Uptake Study: For the deuterated palmitic acid uptake, windows were removed from media after being exposed to $50 \mu \mathrm{M} \mathrm{D}_{31}$-PA for between 15 minutes and 24 hours.

Assembly of the sample holder was again largely consistent with the description above, but with the syringes loaded with serum-free DMEM media, and the second $\mathrm{CaF}_{2}$ window was again of 2 $\mathrm{mm}$ thickness - as the key deuterated palmitic acid peaks are found in the $2050-2300 \mathrm{~cm}^{-1}$ wavenumber region, access to the lower wavenumber was not required.

\section{Measurement}

Viability Study: The heater was set to a temperature of $44{ }^{\circ} \mathrm{C}$, found through preliminary tests to stabilise the sample holder temperature a $37{ }^{\circ} \mathrm{C}$. The syringe pump initiated flow at $10 \mu \mathrm{L} / \mathrm{min}$, which was reduced to $1 \mu \mathrm{L} / \mathrm{min}$ once flow through the sample chamber had been observed. After the required amount of time, the syringe was swapped for one containing a 1:1 solution of complete DMEM media and trypan blue solution, which was flowed through the lines and into the sample chamber. A number of photographs were taken over the course of $\sim 10$ minutes for cell counting and viability calculations.

Thermal Stress Study: The heater was set to obtain a sample temperature of $37^{\circ} \mathrm{C}$. A temperature profile from one replicate of the study is shown in Figure 3. The temperature of the sample holder was monitored and recorded every minute for the duration of the study using a k-type thermocouple slotted into a $1 \mathrm{~mm}$ hole in the side of the stainless steel sample holder as close to the windows as possible. There is a clear temperature lag between the temperature of the water bath and that measured by the thermocouple. It might be expected due to the poor conductivity of the $\mathrm{CaF}_{2}$ windows that the cells may be experiencing an even lower temperature. However the media input tubes re wrapped around the heating water inlet tubes to supply additional internal heating (Fig. 1). We therefore believe any temperature difference is minimal although this has not been directly measured. 


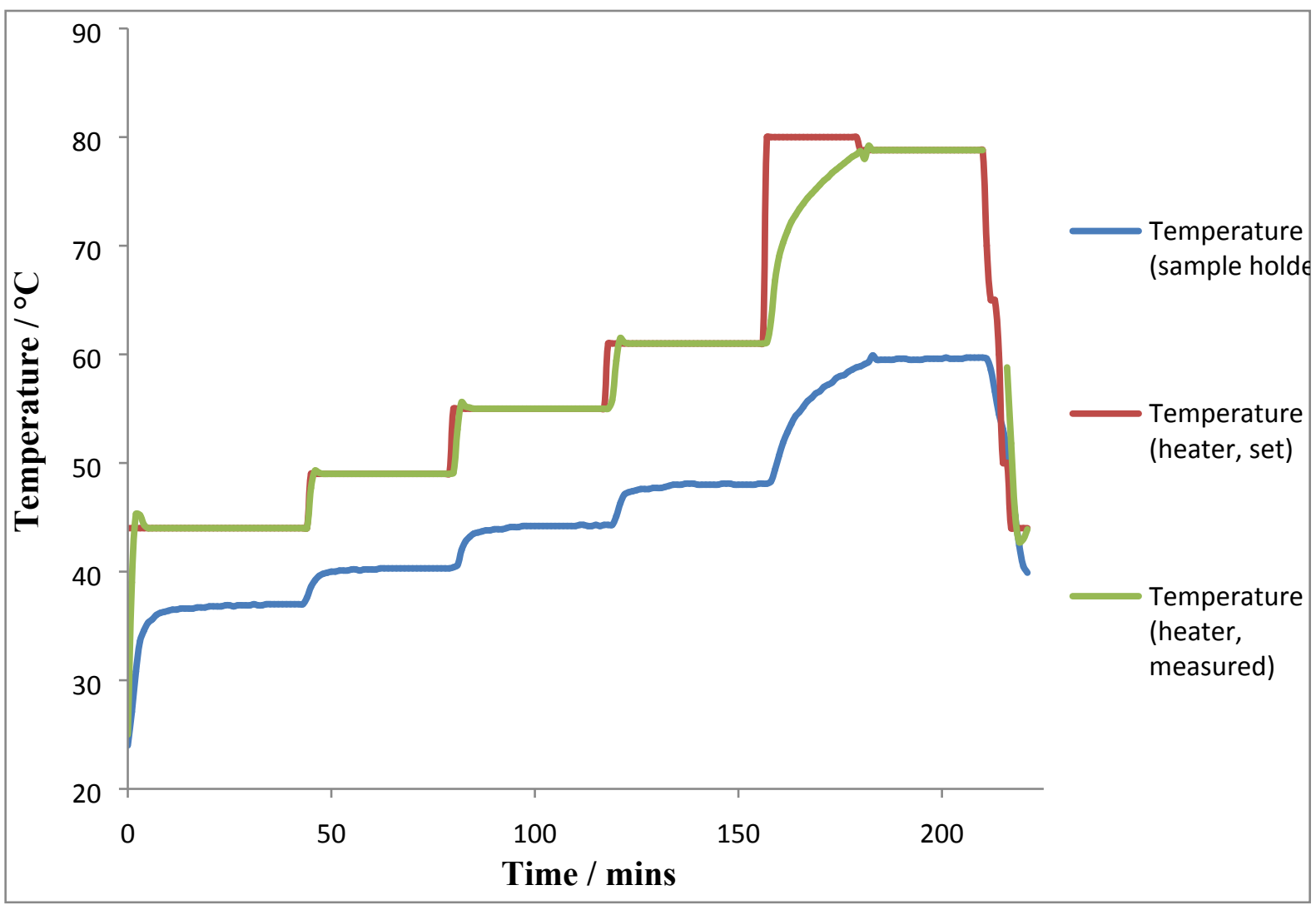

Figure 3 - Temperature profiles, showing the set heater temperature (red), the recorded heater temperature (green) and the recorded temperature of the sample holder (blue), for the duration of a single replicate of the thermal stress study.

A media flow-rate of $10 \mu \mathrm{L} / \mathrm{min}$ was set for approximately 3 minutes, to provide an initial 'flush' of the sample area with fresh media. The flow-rate was then reduced to $1 \mu \mathrm{L} / \mathrm{min}$ for the remainder of the measurement, sufficient to replace the entire sample area with fresh media every few minutes.

When a consistent temperature - defined as varying by no more than $0.1{ }^{\circ} \mathrm{C}$ in either direction for three successive measurements - was achieved, between 10 and 30 cells were measured, with a corresponding media spectrum taken from a cell-free area adjacent to each measured cell. This was for use in future water correction procedures.

Measurements were taken at sample temperatures of $37,40,44,48$ and $60{ }^{\circ} \mathrm{C}$.

Palmitic Acid Uptake Study: The heater was set to achieve a consistent temperature of $37{ }^{\circ} \mathrm{C}$ at the sample holder. Approximately 200 individual cells were measured per loading of the sample holder, with corresponding media spectra taken adjacent to each cell, taking approximately 4 hours to measure. 
A media flow-rate of $10 \mu \mathrm{L} / \mathrm{min}$ was again set for approximately 3 minutes to flush the sample chamber with fresh media, and then reduced to $1 \mu \mathrm{L} / \mathrm{min}$ for the remainder of the measurement.

For both studies, data were collected in transmission mode using the 36x objective/condenser optics on a Hyperion 3000 microscope coupled to a Bruker Vertex 80 FTIR spectrometer at the MIRIAM beamline, B22, at DLS ${ }^{55}$. This used a liquid-nitrogen $\left(\mathrm{LN}_{2}\right)$-cooled mercury-cadmiumtelluride (MCT) high sensitivity 50 micron pitch detector. A $15 \times 15 \mu \mathrm{m}$ aperture was used for the thermal stress study, while a 20x20 $\mu \mathrm{m}$ aperture was used for the measurement of palmitic acid uptake to ensure the cell membrane was captured.

256 co-added scans at a scanner rate of $80 \mathrm{kHz}$ were used for both background and sample measurements, at a spectral resolution of $4 \mathrm{~cm}^{-1}$. This corresponds to approximately $90 \mathrm{IR}$ spectra acquired in $\sim 1$ hour of measurement time, and provides sufficient signal-to-noise for second derivative analysis. Background scans were taken prior to each set of measurements, from a clean, dry area of the sample. All measurements were recorded using OPUS 7.2 software (Bruker).

\section{Data Processing and Analysis}

Thermal Stress Study: The bulk aqueous contribution was removed from each spectrum using an in-house correction procedure, which performs a least squares fit using a Matrigel reference spectrum across to $1700-1500 \mathrm{~cm}^{-1}$ wavenumber range, in order to determine the fraction of the corresponding water spectrum to be subtracted ${ }^{27}$. Spectra from different replicates were combined, and then manually quality controlled using an in-house principal component analysis (PCA)-based method, before the resulting spectra were vector normalised and converted to the second derivative, with a 9 point smoothing filter applied.

The second derivative spectra were split into low and high wavenumber sections, from 1150$1580 \mathrm{~cm}^{-1}$ and $2800-3000 \mathrm{~cm}^{-1}$ respectively. This excluded the Amide I band, which suffered from saturation effects, especially in second derivative. The second derivative spectra were then analysed by computing mean spectra and through supervised multivariate analysis (MVA).

Palmitic Acid Uptake Study: The original spectra were water-corrected as for the thermal stress study, and the resulting spectra then manually quality controlled, normalised to the Amide II band and then cut to the 2050-2300 $\mathrm{cm}^{-1}$ wavenumber range containing the key PA bands of interest. Some baseline variation was detected in this region, likely the result of a combination of residual water signal and slight variations in pathlength in different areas of the sample. This was corrected by performing a $4^{\text {th }}$-order polynomial fit. The corrected spectra were then analysed by computing mean spectra, and measuring the peak area of the key PA bands.

All data processing and analysis was performed in MATLAB.

\section{Results and Discussion}




\section{Cell Viability Test}

The viability of cells maintained in the measurement environment is a crucial initial test of the system. Viability tests were performed at 4 and 24 hours, consistent with the longest sample time used in this experiment, and the time over which future experiments would ideally be performed, respectively. $\sim 1300$ cells were counted at 4 hours, and $\sim 2500$ at 24 hours - as viability was expected to be lower at 24 hours, and that variations in viability by location in the sample holder is a possibility, it was important to count a high number of cells to ensure the viability calculation was robust.

Table 1 summarises the findings of the viability study, with $97.3 \%$ of the counted cells being viable at 4 hours, and $95.7 \%$ being viable after 24 hours. The images shown in Figure 4 are examples of the images counted at each time point and are broadly representative of the proportion of viable and non-viable cells. At both 4 and 24 hours the cells look healthy and do not appear to be compressed. This is as expected since we estimate the maximum height of the cells to be less than $5 \mu \mathrm{m}$ i.e. considerably less than the $10 \mu \mathrm{m}$ gap between the $\mathrm{CaF}_{2}$ windows.

\section{Table 1 - Summary of cell counting and viability calculations of SKOV3 cells at 4 and 24} hours.

\begin{tabular}{|c|c|c|c|}
\hline Time (hours) & Total Viable Cells & Total Non-Viable Cells & \% Viability \\
\hline 4 & 1281 & 36 & 97.3 \\
\hline 24 & 2558 & 116 & 95.7 \\
\hline
\end{tabular}
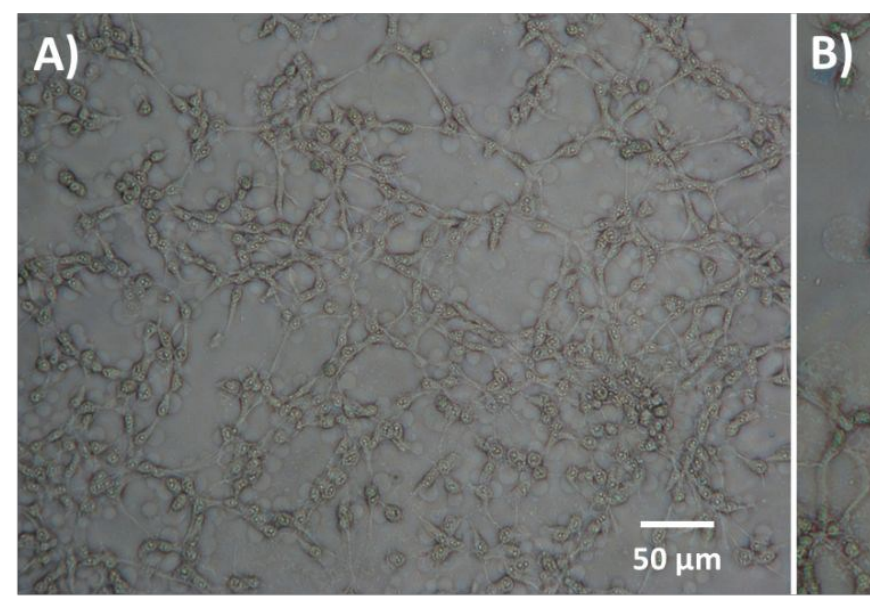

Figure 4 - Sample images from 4 hour (A) and 24 hour (B) staining of SKOV3 cells maintained in the modified liquid sample holder. Stained cells can be clearly seen in $B$.

The results of the viability study are important for two reasons. Firstly, it demonstrates that the proposed system successfully maintains the vast majority of a cell population in a healthy state over the course of 24 hours, opening the possibility of longer-duration single-cell perturbation studies using this system. Secondly, and crucially, it shows that, when selecting an area of cells for measurement, it is statistically likely that the vast majority of cells in a given field of view will be viable, even after 24 hours. This reduces the possibility of cell apoptosis and death 
signatures affecting the measured IR spectra, and subsequently influencing analysis and interpretation of results.

\section{Thermal Stress Study}

Changes in SKOV3 cells at increasing temperature have been analysed through second derivative mean spectra and discriminant function analysis (DFA).

Figure 5 shows second derivative mean spectra of two combined replicates of the thermal stress study, with key peaks that appear to show temperature-based differences in the spectra highlighted. Figure 5A) shows the lipid region, which is relatively consistent across temperatures, with the exception of a slight shift to lower wavenumber with increasing temperature at $2945 \mathrm{~cm}^{-1}$, which is consistent with changes in $\mathrm{C}-\mathrm{H}$ stretching bands with temperature. ${ }^{35}$ The lack of significant changes in the lipid bands is surprising, as changes to the membrane structure were expected with increasing temperature, as well as potentially apoptosis signatures as the cells began to die. ${ }^{2,56,57}$ It is possible that changes to the cells were more gradual than anticipated, and longer exposure to higher temperatures before measurements would have led to some of these changes being observed.

Figure 5B) shows a much wider range of differences in the mean spectra, particularly between the spectrum at $60{ }^{\circ} \mathrm{C}$, shown in red, and those at the remaining temperatures. More specifically, a range of changes are seen in protein bands consistent with changes in structure. ${ }^{58}$ In particular, the collapse of Amide II-related bands at $60{ }^{\circ} \mathrm{C}$ between 1547 and $\sim 1520 \mathrm{~cm}^{-1}$ is a significant structural change, and consistent with published work on temperature induced denaturing of proteins ${ }^{59}$, where a similar collapse of the Amide II was observed at $57{ }^{\circ} \mathrm{C}$. The decrease in Amide II intensity of the $60{ }^{\circ} \mathrm{C}$ spectrum at $1547 \mathrm{~cm}^{-1}$, and corresponding increase at $1514 \mathrm{~cm}^{-1}$, is consistent with an increase in $\beta$-sheet/ $\alpha$-helix ratio with temperature ${ }^{60}$, indicating significant changes in protein structure. The changes in the region around the Amide II band can be seen more clearly in Figure 5C). ${ }^{61}$

Further smaller changes are identified across the spectrum, including deformation of $\mathrm{CH}_{2}$ and $\mathrm{CH}_{3}$ groups in polysaccharides and proteins respectively at 1429 and $1402 \mathrm{~cm}^{-1}$, and possible changes in the Amide III at $1315 \mathrm{~cm}^{-1}$. Changes in Amide III bands have also been identified in work on heat denaturation in single cells measured by Raman spectroscopy. ${ }^{62}$ Furthermore, the increased prominence of the $1228 \mathrm{~cm}^{-1}$ peak at $60^{\circ} \mathrm{C}$ is consistent with reported work that identifies DNA double-helix denaturation at $>52{ }^{\circ} \mathrm{C}^{63}$; unfortunately, the high substrate cut-off renders the lower wavenumber DNA bands, which could have confirmed this change, inaccessible in this case.

While the mean spectra for all cells give an indicator of the key biochemical changes that are occurring with temperature, this analysis does not take into account cell-to-cell variation between the cells. With this in mind, the spectra were also analysed through MVA of the second derivative, low wavenumber spectra. Supervised DFA, retaining principal components (PCs) 
accounting for $95 \%$ of the variance, was used to analysed the spectra; the DFA scores plot of spectra at all five temperatures is shown in Figure 6, with the corresponding loading for DF1 shown in Figure 7.

Examination of Figure 6 shows clear separation between the $60{ }^{\circ} \mathrm{C}$ spectra, shown in red, and the remaining four groups across DF1. The $37{ }^{\circ} \mathrm{C}$ spectra (dark blue) also separate, in the other direction, from the three intermediate temperatures. The separation between the spectra at the intermediate temperatures is less distinct, since thermal stress effects - specifically protein denaturation - have a number of intermediate steps, with significant changes occurring at several temperatures, including $\sim 58^{\circ} \mathrm{C}$. ${ }^{64}$ This likely explains the overlap between the spectra at intermediate temperatures.

Examination of the DF1 loading shown in Figure 7 highlights a number of features of interest. Consistent with the mean spectra in Figure 5, the dominant feature of the loading is changes in the Amide II bands. This includes possible variations in C-N vibrations, likely related to double bond behaviour in the Amide $\mathrm{II}^{65}$ (1531 and $\left.1521 \mathrm{~cm}^{-1}{ }^{35}\right)$, and $\mathrm{CH}_{2}$ scissoring and deformation occurring in lipids (1467 and $1427 \mathrm{~cm}^{-1}$ respectively). These are consistent with the changes seen in mean spectra, and other experiments into temperature effects reported elsewhere. 59, 62, 66

The effects of thermal stress on SKOV3 cells identified here are consistent with other published work on heat-induced changes in both cells and proteins. Alongside general changes identified in lipid and protein bands, specific spectral changes related to $\alpha$-helix to $\beta$-sheet protein changes and denaturation of DNA have been identified, which are consistent in terms of both temperature and peak position with similar work. Importantly these spectra are independent of the water correction method used validating this new approach, see appendix 1. 

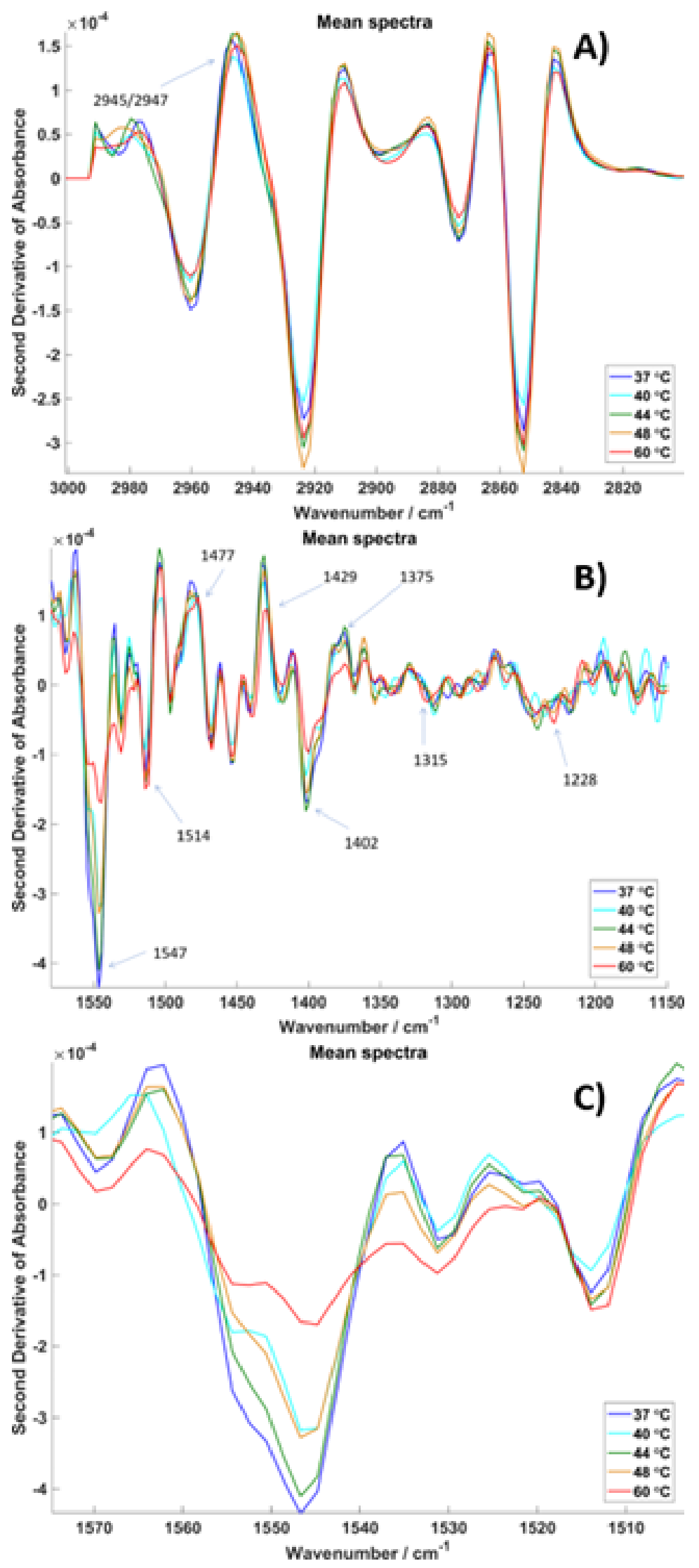

Figure 5 - Second derivative mean spectra of SKOV3 cells at different sample temperatures, separated into high (A) and low (B) wavenumber regions, with the changes around the Amide II band enhanced in C). Key peaks where differences between temperatures are seen are highlighted in A) and B). 


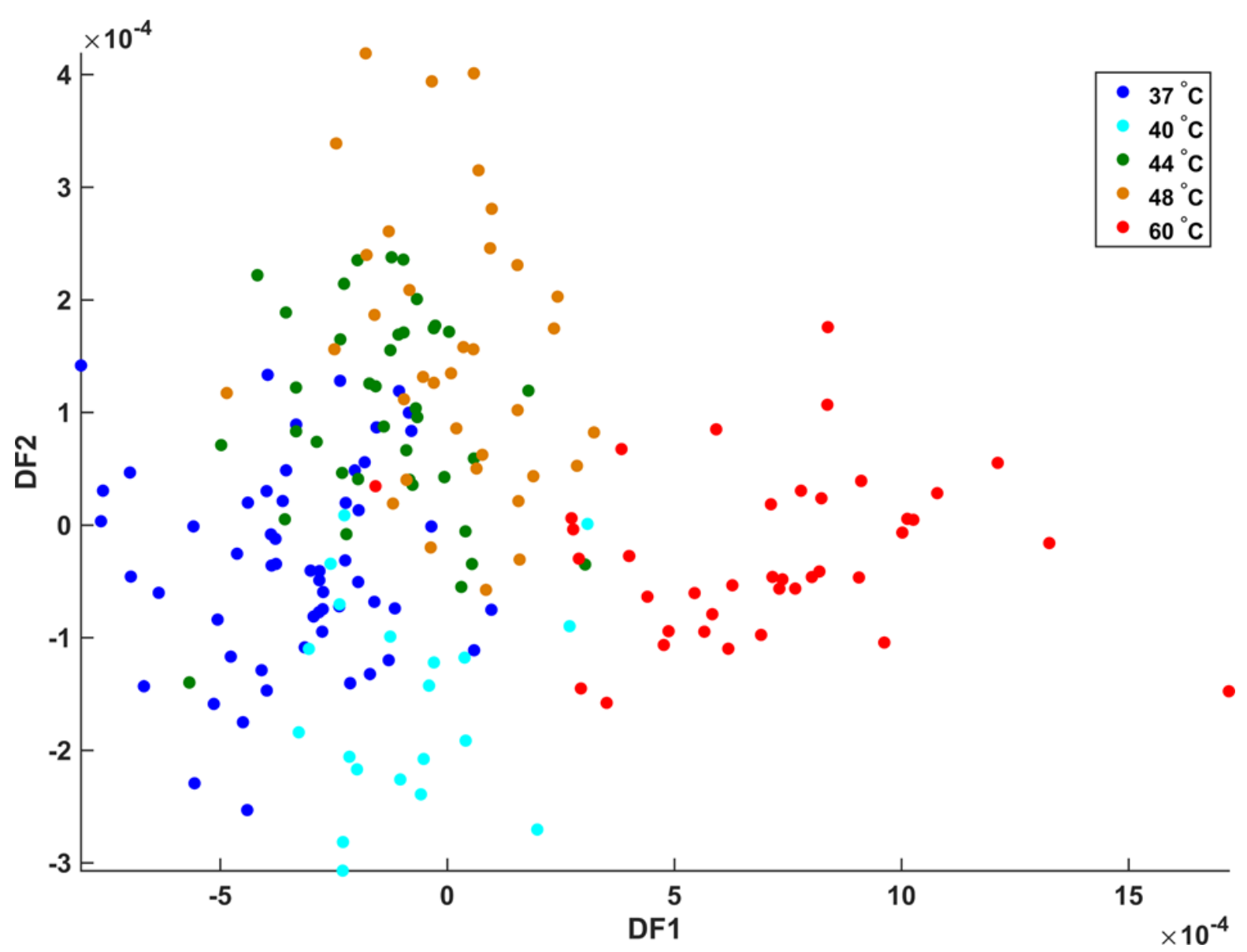

Figure 6 - DFA scores plot of second derivative spectra, cut to the low wavenumber region, at each sample temperature. Clear separation can be seen between $60{ }^{\circ} \mathrm{C}$ (red) and the remaining temperatures. 


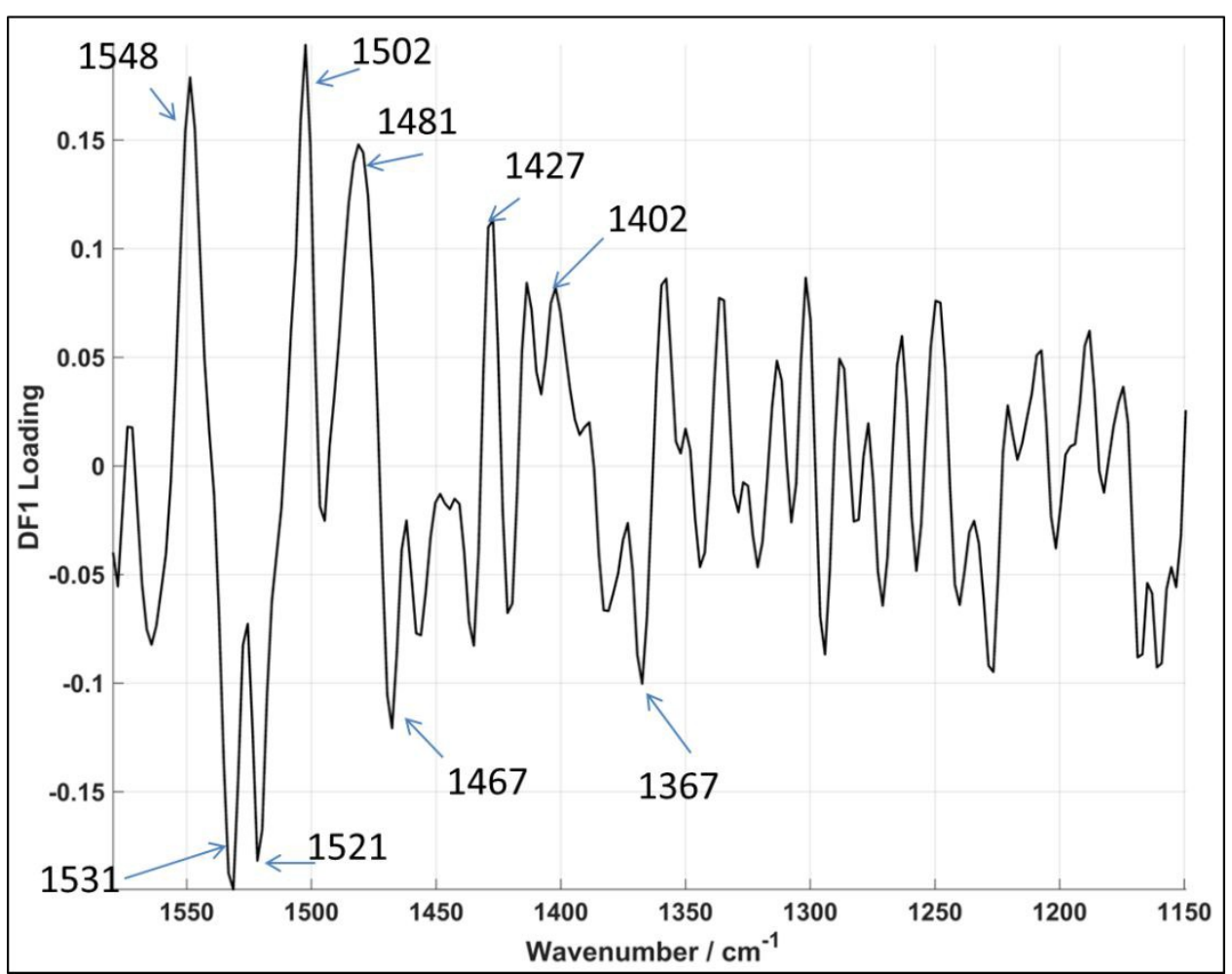

Figure 7 - Corresponding loadings plot for DF1, with key peaks highlighted.

\section{Monitoring Palmitic Acid Uptake}

Monitoring of the uptake of deuterated PA over time involved the collection of a large number of spectra ( 200) from single cells over the course of several hours, while the sample was maintained in the dynamic flow system.

The spectrum of PA is shown in Figure 8, with the additional insert focusing on the region of interest for this study, 2050-2300 $\mathrm{cm}^{-1}$. These cover the symmetric and asymmetric stretching of $\mathrm{C}-\mathrm{D}_{2}$ and $\mathrm{C}-\mathrm{D}_{3}$ groups and fall outside of the main biochemical bands occurring in IR spectra. The intensity of these bands in cell spectra, therefore, is a good indicator of the uptake of PA by the cells at each timepoint. 


\section{Deuterated Palmitic Acid}

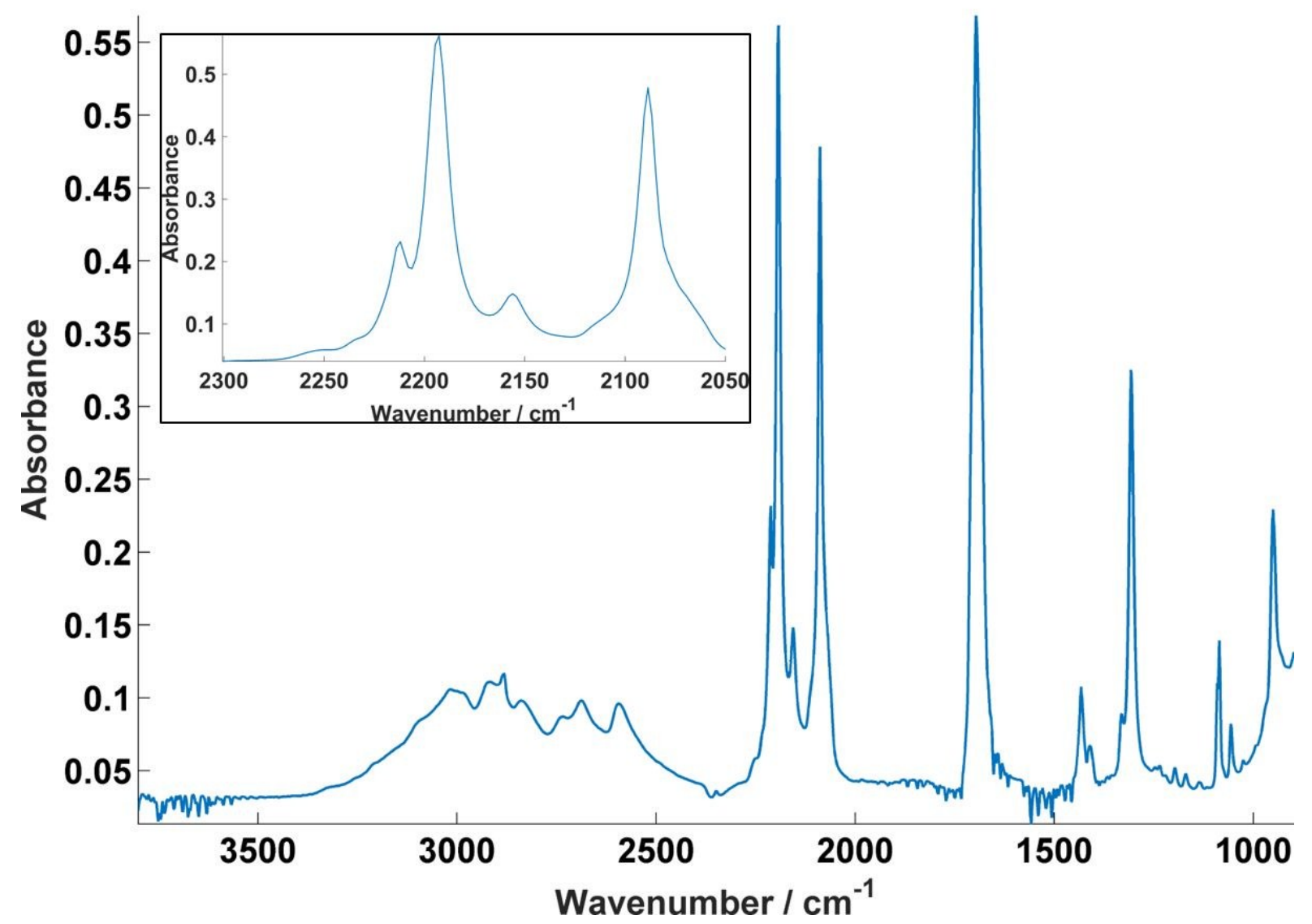

Figure 8 - Spectrum of deuterated palmitic acid. Insert: Spectrum of deuterated palmitic acid cut to $2050-2300 \mathrm{~cm}^{-1}$ wavenumber range.

Mean spectra at each incubation time, cut to show just the PA bands of interest, are shown in Figure 9. Polynomial baseline correction has removed the majority of the variation initially seen in this region, although in the cause of the lower time points, especially at 15 minutes (dark blue), the asymmetric stretching region from $\sim 2150-\sim 2250 \mathrm{~cm}^{-1}$ appears to be better resolved that the symmetric bands at $\sim 2100 \mathrm{~cm}^{-1}$.

Figure 9 clearly shows, however, a consistent increase in the concentration of PA with time, with uptake detectable after just 15 minutes and rapid uptake identifiable up to 90 minutes, with slower uptake thereafter. 


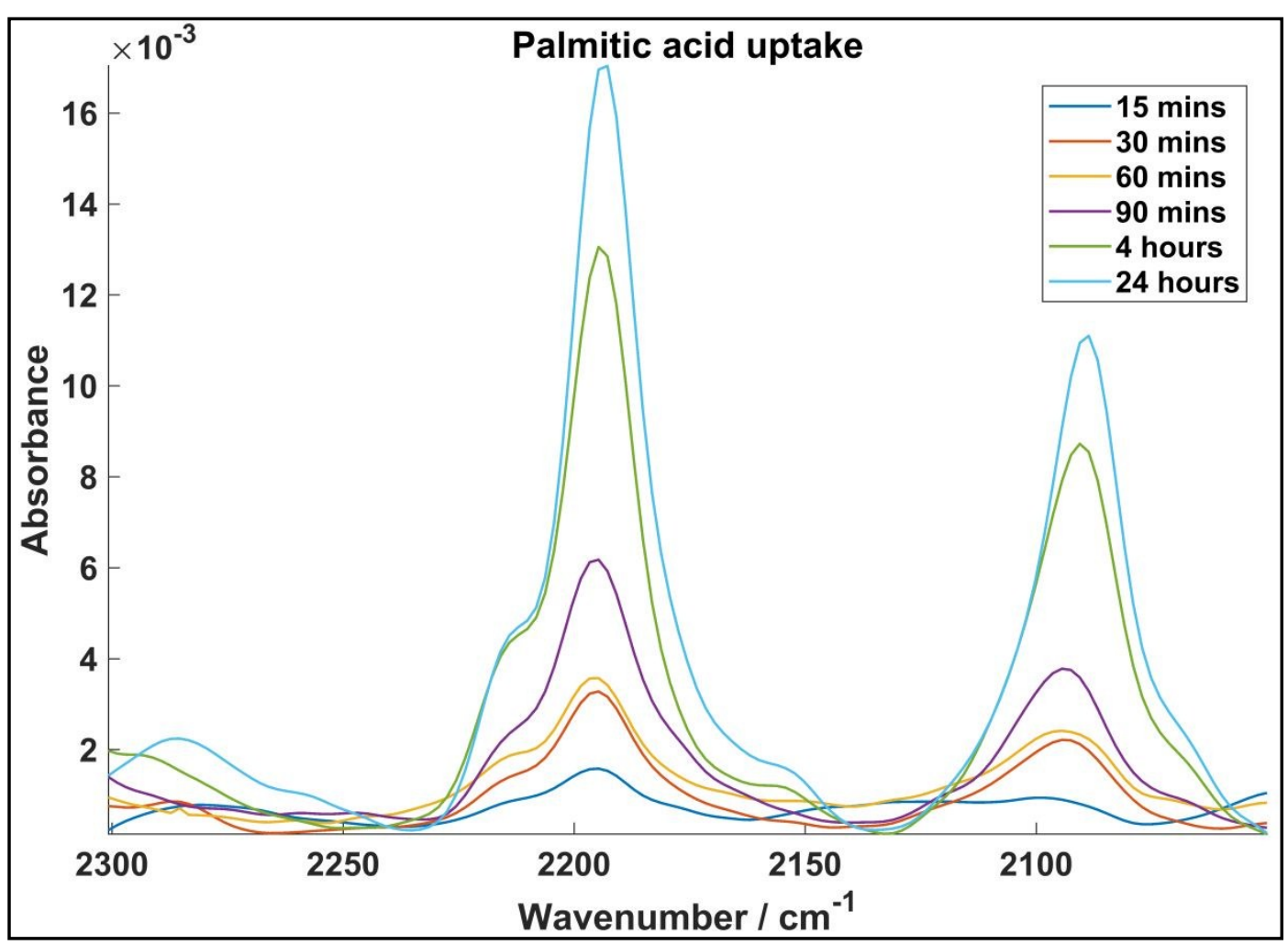

Figure 9 - Mean spectra of deuterated palmitic acid bands at each incubation time.

The ratio of the asymmetric to symmetric bands in Figure 9 appears broadly consistent with that of the pure PA spectrum shown in Figure 8, which is a useful verification of the data processing algorithms employed.

Once again, interpreting the mean spectra does not allow for analysis of the data on a cell-by-cell basis. To do this, the peak area was calculated across the $2137-2235 \mathrm{~cm}^{-1}$ wavenumber range, covering the asymmetric $\mathrm{CD}_{2}$ stretch and the smaller peaks on either side. The peak area calculations were performed in MATLAB on 135 randomly selected spectra from each timepoint - equalising the size of the groups to the smallest set of spectra following quality control - using an algorithm that draws a straight line between the two chosen wavenumber values and then treats the peak as triangle.

The peak areas were visualised using a box-and-whiskers plot, shown in Figure 10; note that the incubation time is shown on a logarithmic scale. The overall trend in uptake across the whole cell population measured on a single cell basis is consistent with observations of the mean spectra. A rapid initial uptake is observed, which then slows considerably after 90 minutes.

Figure 10 shows a significant spread in the data, especially at longer incubation times, suggesting variation in the uptake between individual cells. This highlights the additional insight that can be obtained by performing analysis on a cell-by-cell basis. The variation in uptake has several possible causes; it may be a function of cell cycle, or related to the time for which the cells were 
serum-starved prior to measurement. All samples were serum-starved for between 12 and 24 hours, but the exact time will vary between samples.

Even at the longest incubation times, some cells still show a very low uptake of PA, as evidenced by the lower limit of the box-and-whiskers plot at 240 and 1440 minutes ( 4 and 24 hours respectively). A range of possibilities exist for this variation in uptake, including a degree of cellcycle dependency or the use of FA in metabolic processes in the cell. Increased spread in the uptake of $\mathrm{D}_{31}$-PA at the later incubation times provides scope for further study of cellular metabolic processes and the fate of fatty acids.

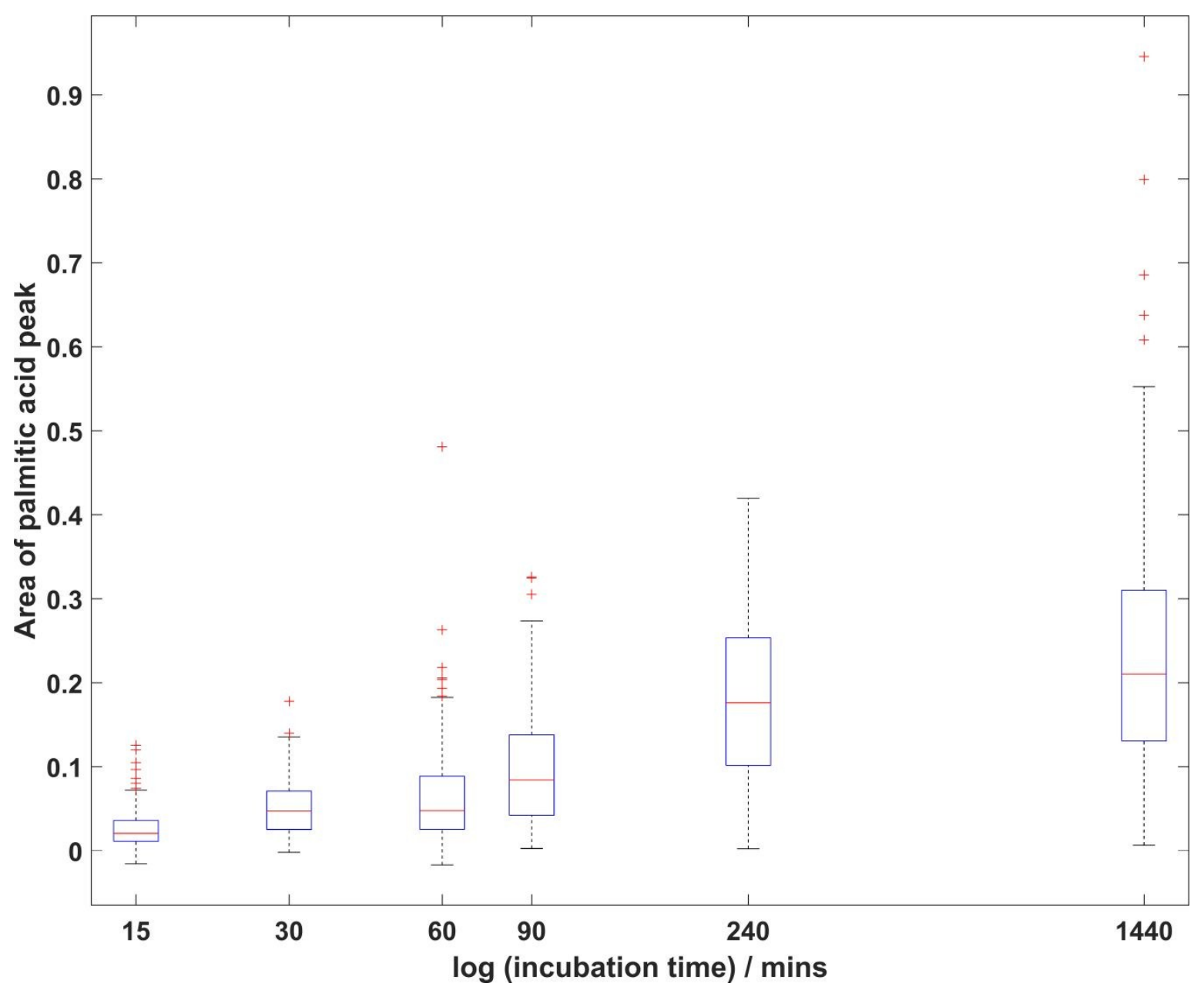

Figure 10 - Box-and-whiskers plot of peak area across the $2137-2235 \mathrm{~cm}^{-1}$ wavenumber range, calculated from 135 randomly selected spectra at each incubation time. The red line represents the median, with the blue box showing the interquartile range, and red crosses being outliers

This study of PA uptake has demonstrated the ability of our proposed dynamic flow live cell system to facilitate the analysis of large numbers of viable cells $(\sim 200)$ in a single loading. This provides much greater scope for capturing cell-to-cell variation in response to a stimulus, while 
also improving the statistical reliability of results by increasing the number of individual spectra from which conclusions can be drawn.

\section{Conclusions}

The work presented here showcases preliminary results from a dynamic live cell measurement system, incorporating medium exchange and temperature control, and demonstrated cell viability up to at least 24 hours through staining with trypan blue.

This dynamic system was developed through simple, cost-effective modifications to an existing commercially available liquid sample holder, allowing media flow to maintain cell viability and the use of high magnification 36x optics for single-cell FTIR microspectroscopy. This relatively straightforward implementation has produced a robust and reproducible system without susceptibility to leaks or window breakages. To our knowledge, the use of a hydrophobic PAP pen to help direct flow in such a system is a new development. Further testing will be performed to improve the consistency of this channel, potentially using a bespoke stencil or similar design.

Two different experiments have been undertaken using SKOV3 ovarian cancer cells, each of which demonstrates a different property of the method. By increasing the sample temperature, and observing significant protein and lipid changes in both mean spectra and DFA, we demonstrate that we are able to simultaneously induce biochemical changes in cells and measure these changes through collection of a relatively small number of spectra. Crucially, the spectral changes seen are consistent with other published work in heat-induced changes in cells and proteins, and specific bands have been identified which correspond to $\alpha-\beta$ transitions.

The study of deuterated palmitic acid uptake highlights the ability to collect large numbers of live cell spectra from a single sample, across a significantly increased timeframe compared to measurements carried out in a static live cell environment. These have shown that the uptake of $\mathrm{D}_{31}$-PA can be clearly seen in the resulting cell spectra, while also raising interesting questions about the subsequent use of PA by the cells and the timeframe over which this occurs. Combined with the results of the trypan blue staining, which demonstrate cell viability of over $95 \%$ after 24 hours assembly in the dynamic flow system, this confirms the ability of our proposed system to maintain live samples for long-term IR study.

By demonstrating cell viability up to 24 hours, we have shown that our proposed method is potentially suitable for a range of live cell applications monitoring cellular changes following exposure to a stimulus. Combined with effective water correction and the brilliance of SR, we have acquired high quality microFTIR spectra from living cells over a significantly extended period of time. At present the system has not been demonstrated on non-adherent cell lines since it is unlikely that they would be stable enough to resist the flow of the media through the cell i.e. we suspect that they would be washed out during the course of the experiment. 
Further work on this system is likely to incorporate improvements to temperature control and monitoring, and better control of $\mathrm{CO}_{2}$ and $\mathrm{O}_{2}$ levels, which could prolong cell viability even further. However, the preliminary studies presented here are a positive first step in the development of a bespoke live cell measurement system for IR microanalysis. In principle the system is not limited to SR FTIR but could also be used on a bench-top system with a globar source but the $\mathrm{S} / \mathrm{N}$ drops dramatically for smaller apertures so scan times would be considerably longer to obtain the same spectral quality ( $\mathrm{S} / \mathrm{N}$ scales with the square root of the acquisition time) (see Supplementary S1).

\section{Acknowledgements}

SKOV3 cells were provided by G. Owens from the Institute for Cancer Science, University of Manchester (UoM). J. Doherty gratefully acknowledges support from DLS and UoM for cofunding for a PhD scholarship. P. Gardner and J. Denbigh further acknowledge DLS for beamtimes SM18968-1 and SM19084-1. S. Daniels at DLS is acknowledged for support with technical equipment design, as is L. Quaroni (Faculty of Chemistry, Jagiellonian University, Poland) for providing spacers. Thanks to A. Henderson at UoM for support with data processing, and all the team at the B22 MIRIAM beamline at DLS. J. Denbigh gratefully acknowledges Kidscan Children's Cancer Research for support for Ansaf Hussain.

\section{References}

1. A. B. de Carvalho, M. Pilling, P. Gardner, J. Doherty, G. Cinque, K. Wehbe, C. Kelley, L. B. de Carvalho and M. P. M. Marques, Faraday discussions, 2016.

2. J. L. Denbigh, D. Perez-Guaita, R. R. Vernooij, M. J. Tobin, K. R. Bambery, Y. Xu, A. D. Southam, F. L. Khanim, M. T. Drayson and N. P. Lockyer, Scientific Reports, 2017, 7.

3. J. Doherty, G. Cinque and P. Gardner, Applied Spectroscopy Reviews, 2017, 52, 560-587.

4. K. R. Flower, I. Khalifa, P. Bassan, D. Démoulin, E. Jackson, N. P. Lockyer, A. T. McGown, P. Miles, L. Vaccari and P. Gardner, Analyst, 2011, 136, 498-507.

5. C. Hughes, M. Brown, F. Ball, G. Monjardez, N. Clarke, K. Flower and P. Gardner, Analyst, 2012, 137, 5736-5742.

6. C. Hughes, M. Brown, N. Clarke, K. Flower and P. Gardner, Analyst, 2012, 137, 47204726.

7. M. Jimenez-Hernandez, M. D. Brown, C. Hughes, N. W. Clarke and P. Gardner, Analyst, 2015, 140, 4453-4464.

8. M. Siddique, A. Rutter, K. Wehbe, G. Cinque, G. Bellisola and J. Sulé-Suso, Analyst, 2017, 142, 1299-1307.

9. G. Birarda, G. Grenci, L. Businaro, B. Marmiroli, S. Pacor, F. Piccirilli and L. Vaccari, Vibrational spectroscopy, 2010, 53, 6-11.

10. G. Clemens, K. R. Flower, A. P. Henderson, A. Whiting, S. A. Przyborski, M. JimenezHernandez, F. Ball, P. Bassan, G. Cinque and P. Gardner, Molecular BioSystems, 2013, 9, 677-692.

11. E. Gazi, T. J. Harvey, M. D. Brown, N. P. Lockyer, P. Gardner and N. W. Clarke, Vibrational spectroscopy, 2009, 50, 99-105. 
12. P. Heraud, B. R. Wood, M. J. Tobin, J. Beardall and D. McNaughton, FEMS Microbiology Letters, 2005, 249, 219-225.

13. D. A. Moss, M. Keese and R. Pepperkok, Vibrational spectroscopy, 2005, 38, 185-191.

14. K. L. Munro, K. R. Bambery, E. A. Carter, L. Puskar, M. J. Tobin, B. R. Wood and C. T. Dillon, Vibrational spectroscopy, 2010, 53, 39-44.

15. L. Quaroni and T. Zlateva, Analyst, 2011, 136, 3219-3232.

16. K. A. Chan, P. L. Fale, A. Atharawi, K. Wehbe and G. Cinque, Anal Bioanal Chem, 2018, 1-11.

17. E. Gazi, J. Dwyer, N. P. Lockyer, J. Miyan, P. Gardner, C. Hart, M. Brown and N. W. Clarke, Biopolymers, 2005, 77, 18-30.

18. F. M. Lyng, E. Gazi and P. Gardner, in Biomedical Applications of Synchrotron Infrared Microspectroscopy, ed. D. Moss, Royal Society of Chemistry, 2011.

19. L. Vaccari, G. Birarda, L. Businaro, S. Pacor and G. Grenci, Analytical Chemistry, 2012, 84, 4768-4775.

20. A. Pevsner and M. Diem, Applied Spectroscopy, 2001, 55, 788-793.

21. A. Pevsner and M. Diem, Applied Spectroscopy, 2001, 55, 1502-1505.

22. A. Pevsner and M. Diem, Biopolymers, 2003, 72, 282-289.

23. D. R. Whelan, K. R. Bambery, P. Heraud, M. J. Tobin, M. Diem, D. McNaughton and B. R. Wood, Nucleic acids research, 2011, 39, 5439-5448.

24. B. R. Wood, Chemical Society Reviews, 2016, 45, 1980-1998.

25. A. J. Bentley, T. Nakamura, A. Hammiche, H. M. Pollock, F. L. Martin, S. Kinoshita and N. J. Fullwood, Molecular vision, 2007, 13, 237.

26. G. Cinque, M. D. Frogley, K. Wehbe, T.-N. Q. Nguyen, A. Fitzpatrick and C. S. Kelley, Synchrotron Radiation News, 2017, 30, 11-16.

27. J. Doherty, Z. Zhang, K. Wehbe, G. Cinque, P. Gardner and J. Denbigh, Anal Bioanal Chem, 2018, 1-11.

28. K. L. Goff, L. Quaroni and K. E. J. A. Wilson, 2009, 134, 2216-2219.

29. H.-Y. N. Holman, H. A. Bechtel, Z. Hao and M. C. Martin, Analytical Chemistry, 2010, 82, 8757-8765.

30. H.-Y. N. Holman, Z. Hao, M. C. Martin and H. A. Bechtel, Synchrotron Radiation News, 2010, 23, 12-19.

31. H.-Y. N. Holman, M. C. Martin and W. R. McKinney, Journal, 2002.

32. A. Marcelli and G. Cinque, in Biomedical applications of synchrotron infrared microspectroscopy, 2010, pp. 67-104.

33. L. Quaroni, T. Zlateva and E. Normand, Analytical Chemistry, 2011, 83, 7371-7380.

34. E. J. Marcsisin, C. M. Uttero, M. Miljkovic and M. Diem, Analyst, 2010, 135, 32273232.

35. Z. Movasaghi, S. Rehman and D. I. ur Rehman, Applied Spectroscopy Reviews, 2008, 43, 134-179.

36. A. Dong, P. Huang and W. S. Caughey, Biochemistry, 1990, 29, 3303-3308.

37. J. R. Mourant, R. R. Gibson, T. M. Johnson, S. Carpenter, K. W. Short, Y. R. Yamada and J. P. Freyer, Physics in medicine and biology, 2003, 48, 243.

38. P. Gelfand, R. J. Smith, E. Stavitski, D. R. Borchelt and L. M. Miller, Analytical Chemistry, 2015.

39. L. Quaroni, T. Zlateva, K. Wehbe and G. Cinque, Faraday discussions, 2016. 
40. B. Alberts, A. Johnson, J. Lewis, M. Raff, K. Roberts and P. Walter, Molecular Biology of the Cell, Garland Science, New York, 2002.

41. J. Paul, R. Provencal and R. Saykally, The Journal of Physical Chemistry A, 1998, 102, 3279-3283.

42. L. Quaroni, T. Zlateva, B. Sarafimov, H. W. Kreuzer, K. Wehbe, E. L. Hegg and G. Cinque, Biophysical chemistry, 2014, 189, 40-48.

43. G. Carr, L. Miller and P. Dumas, Journal, 2011.

44. P. Cioni and G. B. Strambini, Biophysical journal, 2002, 82, 3246-3253.

45. L. S. Hohlefelder, T. Stögbauer, M. Opitz, T. M. Bayerl and J. O. Rädler, BioMed research international, 2013, 2013.

46. L. A. Manson, R. I. Carp, V. Defendi, E. L. Rothstein, R. W. Hartzell and D. Kritchevsky, Annals of the New York Academy of Sciences, 1960, 84, 685-694.

47. L. Vaccari, G. Birarda, G. Grenci, S. Pacor and L. Businaro, 2012.

48. G. L. Carr, O. Chubar and P. Dumas, in Spectrochemical Analysis Using Infrared Multichannel Detectors, Blackwell Publishing Ltd, 2007, DOI: 10.1002/9780470988541.ch3, pp. 56-84.

49. P. Dumas, G. D. Sockalingum and J. Sule-Suso, Trends in biotechnology, 2007, 25, 4044.

50. E. W. K. Young and D. J. Beebe, Chemical Society reviews, 2010, 39, 1036-1048.

51. M. J. Tobin, L. Puskar, R. L. Barber, E. C. Harvey, P. Heraud, B. R. Wood, K. R. Bambery, C. T. Dillon and K. L. Munro, Vibrational spectroscopy, 2010, 53, 34-38.

52. G. Birarda, G. Grenci, L. Businaro, B. Marmiroli, S. Pacor and L. Vaccari, Microelectronic Engineering, 2010, 87, 806-809.

53. PAP Pen Super-Liquid Blocker Mini, https://www.cosmobio.com/contents/detail.php?product_id=5622, (accessed 26th July, 2018).

54. PAP pen for immunostaining, https://www.sigmaaldrich.com/catalog/product/sigma/z377821?lang=en\&region=GB\&ut m_term=pap-

pen\&utm_medium $=$ cpc\&utm_content $=$ SIGMA/Z377821\&utm_source=bing\&utm_camp aign $=$ Labware $\% 20-\% 20$ Sigma $\% 20$ etc\%20(transfer)\%20(Bing\%20ebizpfs), (accessed 26th July, 2018).

55. G. Cinque, M. Frogley, K. Wehbe, J. Filik and J. Pijanka, Synchrotron Radiation News, 2011, 24, 24-33.

56. F. Gasparri and M. Muzio, Biochemical Journal, 2003, 369, 239-248.

57. K.-Z. Liu, L. Jia, S. M. Kelsey, A. Newland and H. Mantsch, Apoptosis, 2001, 6, 269278.

58. A. Barth, Biochimica et Biophysica Acta (BBA)-Bioenergetics, 2007, 1767, 1073-1101.

59. I. Van Stokkum, H. Linsdell, J. Hadden, P. I. Haris, D. Chapman and M. Bloemendal, Biochemistry, 1995, 34, 10508-10518.

60. R. I. Litvinov, D. A. Faizullin, Y. F. Zuev and J. W. Weisel, Biophysical journal, 2012, 103, 1020-1027.

61. W. F. Wolkers and H. Oldenhof, Journal of Spectroscopy, 2010, 24, 525-534.

62. C. Xie, Y.-q. Li, W. Tang and R. J. Newton, Journal of Applied Physics, 2003, 94, 61386142. 
63. E. V. Hackl and Y. P. Blagoi, Biopolymers: Original Research on Biomolecules, 2005, 77, 315-324.

64. X. He, W. F. Wolkers, J. H. Crowe, D. J. Swanlund and J. C. Bischof, Annals of biomedical engineering, 2004, 32, 1384-1398.

65. H. Sigel and R. B. Martin, Chemical Reviews, 1982, 82, 385-426.

66. D. Graff, B. Pastrana-Rios, S. Y. Venyaminov and F. G. Prendergast, Journal of the American Chemical Society, 1997, 119, 11282-11294. 


\section{Doherty et al - Graphical Abstract}

A simple, cost-effective liquid sample holder to perform single live cell analysis under an IR microscope

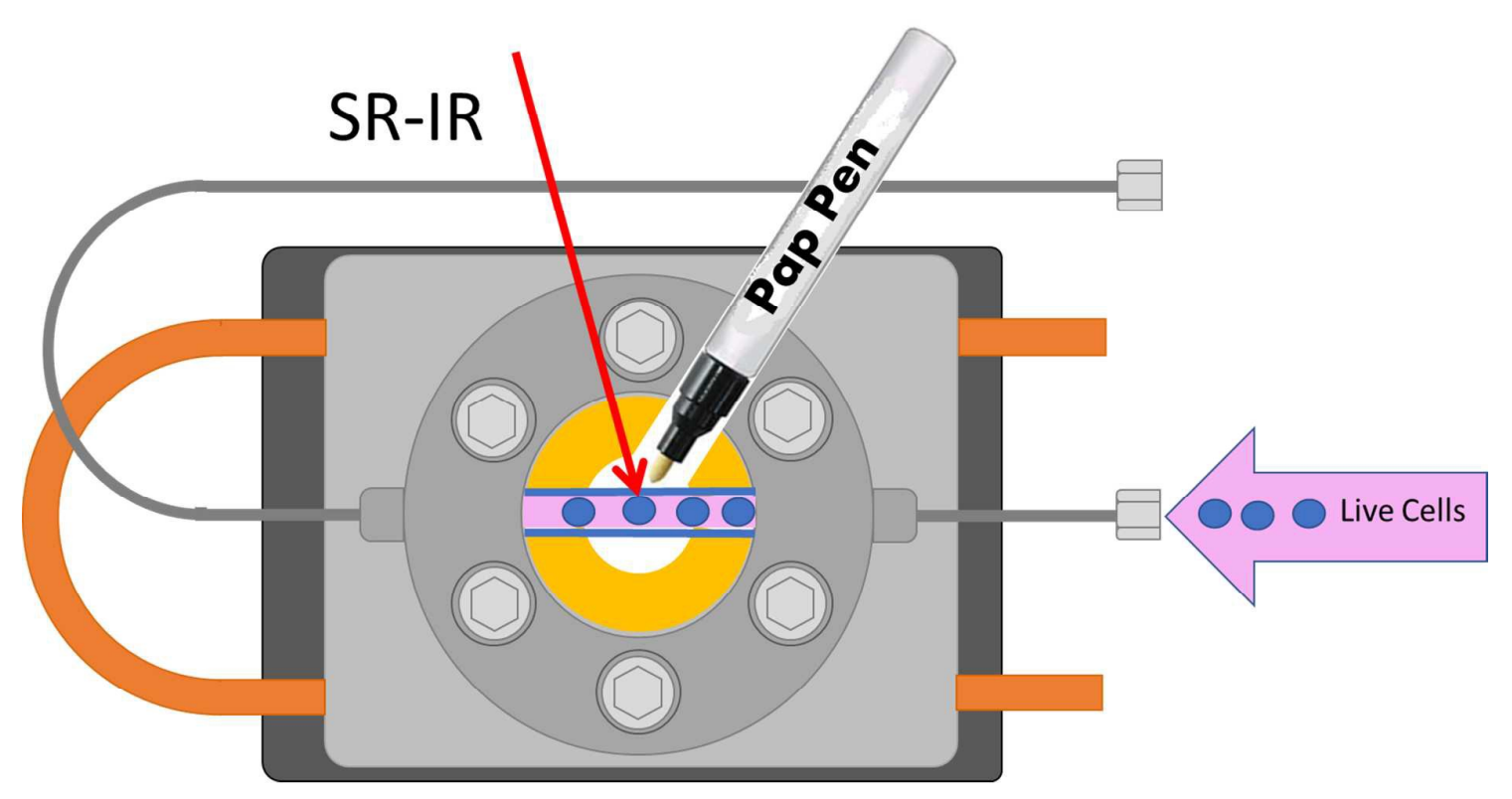

